\title{
Pengembangan Potensi Atraksi Wisata Seni Suara dan Musik di Kampoeng Wisata Titik Nol Jateng, Desa Bligo, Magelang
}

Purwanto Lephen', Budi Raharja², dan Mahdi Naufal Hilmi ${ }^{3}$

${ }^{1}$ Program Studi Teater, Fakultas Seni Pertunjukan ${ }^{2} J u r u s a n$ Pendidikan Seni Pertunjukan, Fakultas Seni Pertunjukan Institut Seni Indonesia Yogyakarta Jalan Parangtritis Km 6,5 Sewon, Bantul, Daerah Istimewa Yogyakarta 55188 No. Tlp.: ${ }^{1}+6218515154,{ }^{2}+6289668911544$ E-mail: ${ }^{1}$ lephenpurwanto@isi.ac.id, ${ }^{2}$ budiraharja51@gmail.com 


\title{
Pengembangan Potensi Atraksi Wisata Seni Suara dan Musik di Kampoeng Wisata Titik Nol Jateng, Desa Bligo, Magelang
}

\author{
Purwanto Lephen ${ }^{1}$, Budi Raharja ${ }^{2}$, dan Mahdi Naufal Hilmi ${ }^{3}$ \\ ${ }^{1}$ Program Studi Teater, Fakultas Seni Pertunjukan \\ ${ }^{2}$ Jurusan Pendidikan Seni Pertunjukan, Fakultas Seni Pertunjukan \\ Institut Seni Indonesia Yogyakarta \\ Jalan Parangtritis Km 6,5 Sewon, Bantul, Daerah Istimewa Yogyakarta 55188 \\ No. Tlp.: ${ }^{1}+6218515154,{ }^{2}+6289668911544$ \\ E-mail: ${ }^{1}$ lephenpurwanto@isi.ac.id, ${ }^{2}$ budiraharja51@gmail.com
}

\begin{abstract}
Abstrak
Kampoeng Wisata Titik Nol Jateng di Blaburan, Bligo, Ngluwar, Magelang, Jawa Tengah memiliki peluang untuk berkembang sebagai desa wisata minat khusus, olah raga, wisata edukasi, dan budaya di perbatasan Jawa Tengah dan Yogyakarta. Potensi wisata tersebut perlu dikembangkan dengan memberdayakan anak-anak dan remaja bermain musik dan berseni suara. Motode pemberdayaan dan pengembangan dilakukan dengan observasi, pendataan, pengklasifikasian, wawancara, dan uji kemampuan menyanyi dan bermusik. Sesudah data peserta pembinaan seni suara dan musik dihimpun, dilakukan uji kepercayaan diri tampil di depan umum. Selanjutnya dilaksanakan pengembangan sumber daya manusia yang berminat pada penguatan bakat menyanyi dan bermusik hingga mampu tampil di depan umum. Pelatihan diikuti 65 peserta dari berbagai desa. Materi yang diajarkan: menyanyi (seni suara) dan seni musik sehingga dapat dibuat atraksi wisata menyanyi lagu anak, lagu remaja, lagu Korea, dan menyanyi bersama (koor), baik lagu pop Jawa maupun Indonesia dan Korea. Bakat-bakat penyanyi dan bermusik di Desa Bligo tersebut dapat memperkuat atraksi wisata musik dan seni suara di Kampoeng Wisata Titik Nol Jateng yang pada tahun 2018-2019 sebanyak 12.100 pengunjung atau rata-rata 500 orang per bulan. Atraksi wisata saat istirahat atau makan biasanya belum ada hiburan. Potensi anak-anak dan remaja dalam bidang musik dan seni suara akan memperkaya atraksi wisata di tepi Sungai Krasak tersebut dapat menyejahterakan warga setempat.
\end{abstract}

Kata kunci: atraksi wisata, seni musik, pemberdayaan 


\section{PENDAHULUAN}

Desa Bligo merupakan desa perbatasan Jawa Tengah dan Daerah Istimewa Yogakarta; memiliki potensi sumber daya alam yang indah dan masyarakat sebagian besar hidup dari berpenghasilan dari bertani, sebagian kecil buruh serta pegawai negeri dan swasta. Sebelah selatan berbatasan dengan Kali Progo, sebelah utara Kali Krasak, dan sebelah barat serta timur Desa Margodadi, Seyegan, Sleman. Jumlah penduduk 5.327 jiwa, terdiri atas 2.648 lelaki dan 2.679 perempuan (Data Kependudukan Desa Bligo, 2019). Desa Bligo, Kecamatan Ngluwar, Kabupaten Magelang terdiri atas 12 dusun, yaitu Jetis, Gagan, Krajan, Kolodanan, Cabeyan, Curah Lor, Curah Kidul, Macanan, Beteng, Blaburan, Bakalan Kidul, dan Bakalan Lor.

Data jenis kelompok kesenian di Desa Bligo hingga tahun 2019 adalah sebagai berikut.

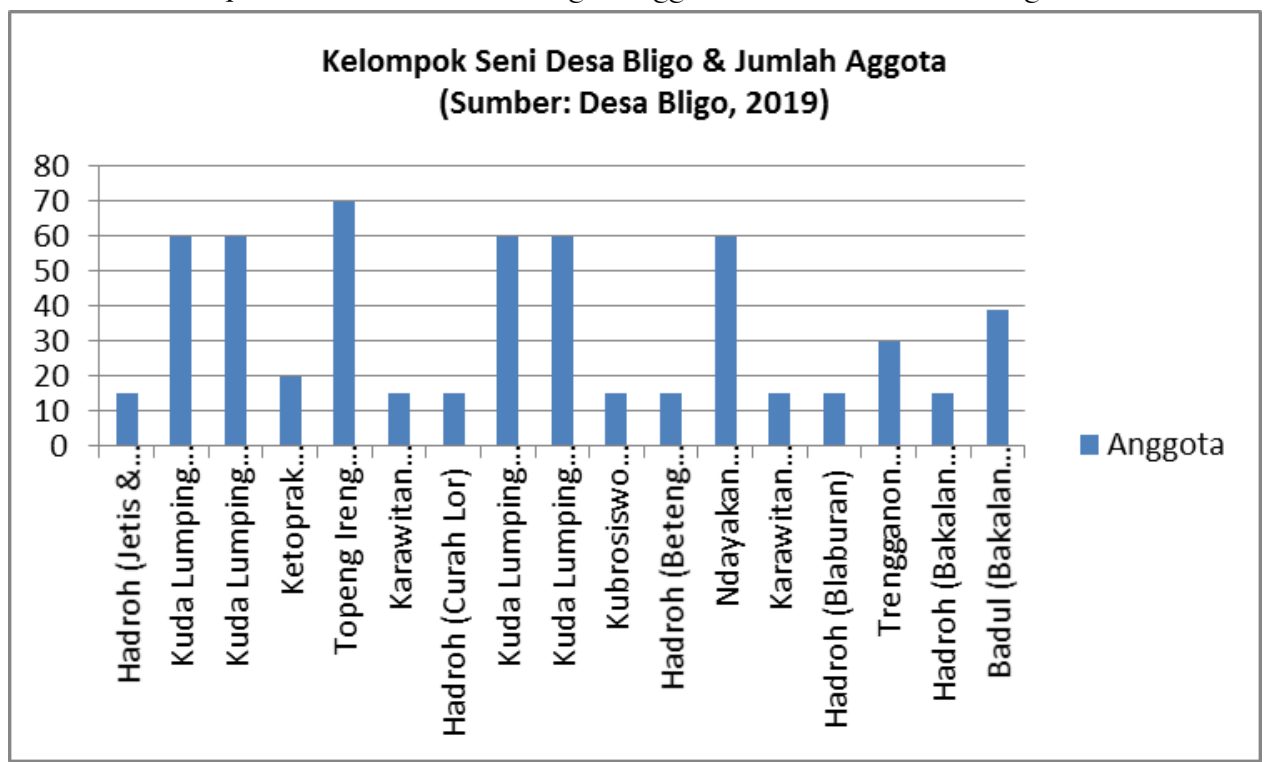

Grafik 1 Data kelompok seni tradisi di Desa Bligo, Ngluwar, Magelang

(Sumber: Data Desa Bligo, Januari 2019)

Desa Bligo memiliki dua lokasi wisata rintisan, yaitu Desa Wisata Ancol di sekitar Bendungan Kali Progo dan Kampoeng Wisata Titik Nol Jateng di Dusun Blaburan. Kampoeng Wisata Titik Nol Jateng semula sebagai sentra olahraga panahan, kemudian dikembangkan menjadi "Kampoeng Wisata Titik Nol Jawa Tengah” oleh Pemerintah Desa Bligo bersama Karang Taruna Dusun Blaburan serta para tokoh masyarakat. Dari sentra pelatihan olah raga panahan lalu dikembangkan ke berbagai atraksi wisata, seperti ice breaking, panahan, polo air, susur sungai, piring terbang, dan main paralon.
Upaya pengembangan potensi seni dan budaya serta wisata alam dan olahraga di Desa Bligo mengalami beberapa kendala yang memerlukan solusi, yaitu: (1) regenerasi grup kesenian tradisional sudah mendesak karena sebagian besar kesenian didukung oleh orang tua yang berusia 55 tahun ke atas; (2) anak muda kurang menyukai dan terpanggil menyukai seni tradisi yang ada sehingga grup kesenian belum dilakukan regenerasi atau upaya melibatkan anak-anak dan anak muda; dan (3) kebutuhan atraksi wisata di kampung atau desa wisata yang ada (Desa Wisata Ancol dan Kampoeng Wisata Titik 0 Jateng) belum 
sinergis sehingga perlu dilakukan upaya kerja sama yang saling menguntungkan.

Oleh karena itu, kehadiran sumber daya pelatih seni tradisi oleh mahasiswa dan dosen dalam P3 Wilsen ISI Yogyakarta mulai 11 Juli sampai dengan 19 Agustus 2019 akan dapat membantu mengudar solusi agar anak-anak muda peduli pada pelestarian seni tradisi dan memiliki nilai tambah serta ekonomis jika dilakukan kerja sama yang terbuka, menguntungkan pengelola Kampoeng Wisata Titik Nol Jateng untuk masa perintisan ataupun masa mendatang yang lebih baik secara ekonomis nilai karya dan sajian seni tradisi yang ada di Desa Bligo.

Anak-anak dan pemuda-pemudi Blaburan dan pemuda Desa Bligo lebih suka pada kesenian modern seperti dangdut, KPop, film, dan pentas gemerlap dengan tata rias dan tata busana yang mewah seperti di televisi atau film dan media sosial Youtube. Oleh sebab itu, perlu ada pelatihan tata rias, pengelolaan atraksi wisata atau event tertentu, pentas tari modern dengan dasar tari tradisi, hingga membuat karya baru dari komunitas seni tradisi yang ada. Hubungan antara seni tradisi dan keadaan anak 'Zaman Now' dapat disinergikan sehingga dapat mengembangkan potensi seni tradisi yang banyak ragamnya di Desa Bligo dan perkembangan wisata di Titik 0 Jateng yang makin baik dengan menghadirkan pewisata rata-rata 200 orang per minggu. Kesukaan pada media modern seperti media sosial juga akan dijadikan media promosi dan kebanggaan diri anak-anak Blaburan dan Desa Bligo untuk kreatif dan inovatif pada Era Generasi 4.0.

Komunitas pembinaan seni suara dan musik di Kampoeng Wisata Titik Nol Jateng ada tiga, yakni di Dusun Blaburan, Dusun Curah (Desa Bligo), dan Dusun Jetis (Desa Pakunden), Ngluwar, Magelang, Jawa Tengah. Kegiatan pembinaan seni suara dan musik mencakup teori dasar musik, teknik menyanyi, dan paduan suara (koor). Di Dusun Blaburan, Bligo, Ngluwar, Magelang, Jawa Tengah ini terdapat sembilan peserta yang aktif mengikuti program pembinaan seni suara dan musik, P3 Wilsen ISI Yogyakarta. Peserta aktif mengikuti kegiatan tersebut. Dalam pembinaan seni musik dan seni suara di Dusun Blaburan, para peserta diajarkan bagaimana cara memosisikan jari (penjarian) yang benar dan pengenalan nada dasar di piano atau keyboard. Adapun di Dusun Curah, Bligo, Ngluwar, Magelang yang mengikuti kegiatan pembinaan seni suara dan musik ini kebanyakan diikuti oleh anak-anak di bawah usia 12 tahun.

Pariwisata merupakan aktivitas perjalanan yang dilakukan sementara waktu ke daerah tujuan untuk tidak menetap atau mencari nafkah, tetapi memenuhi rasa ingin tahu, menghabiskan waktu senggang, libur, dan tujuan lainnya (Zalukhu, 2009). Salah satu tujuan pewisata adalah desa wisata atau kampong wisata yang berbasis komunitas. Pewisata membutuhkan hiburan dan aneka kegiatan yang menarik, unik, dan berkesan yang digarap dan didukung oleh masyarakat setempat. Oleh sebab itu, destinasi atau desa wisata yang dituju pewisata perlu dikelola dengan baik dengan memberdayakan masyarakat setempat. Pengelola destinasi dan atraksi wisata harus mengacu pada prinsipprinsip pengelolaan yang mengacu pada nilainilai kelestarian alam, komunitas, dan nilai sosial budaya yang diminati pewisata yang bermanfaat pada kesejahteraan masyarakat setempat (Arista dan Sutarya, 2017:117). Jadi, atraksi wisata di desa wisata perlu dikembangkan dan ditingkatkan kualitasnya, tetap melibatkan komunitas dan dikelola secara berkelanjutan agar bermanfaat bagi masyarakat setempat dan para pewisata yang datang ke destinasi tersebut.

Pengembangan desa wisata (kampung wisata) perlu memerhatikan kemampuan dan 
tingkat penerimaan masyarakat setempat sebagai pihak pengelola (Putri, 2016:504). Oleh karenanya, pengembangan atraksi wisata dan variasi dengan penyajiannya senantiasa memerhatikan potensi minat seni dan budaya masyarakat setempat. Seni tradisi di Desa Bligo, Ngluwar, Magelang mempunyai banyak ragam seni tradisi. Namun, generasi muda kurang berminat pada seni tradisi dan lebih menyukai seni suara dan musik, baik dangdut, campursari, hingga lagu pop Korea yang potensial dan dapat menjadi karya atraksi wisata yang menarik dengan memberdayakan masyarakat setempat.

\section{METODE PENGABDIAN}

Metode pengabdian dengan cara riset dan pengembangan atau pemberdayaan masyarakat setempat sesuai minat dan bakatnya. Pada langkah awal didata para peminat dan berbakat menyanyi dan bermusik di Desa Bligo. Data calon peserta pembinaan seni suara dan musik diklasifikasi berdasarkan minat dan bakat serta kemampuan awal sebelum dilakukan pembinaan. Metode pengabdian dan pembinaan seni suara dan musik menggunakan metode riset dan pengembangan agar hal-hal yang dikaji di Desa Bligo dapat diterapkan di masyarakat. Riset adalah kegiatan berpikir, melihat, dan mendengar serta membaca (Machfudz, 2012:3). Kegiatan riset awal tersebut kemudian dikembangkan dengan kegiatan nyata dalam masyarakat yang dijadikan subjek yang dikaji. Riset dan pengembangan berdampak positif terhadap pertumbuhan ekonomi (Khaliq, 2020:117). Oleh sebab itu, metode pemberdayaan dan pengembangan potensi atraksi wisata di Kampoeng Wisata Titik Nol Jateng, Desa Bligo dilakukan dengan observasi, pendataan, pengklasifikasian, wawancara, dan uji kemampuan menyanyi dan bermusik. Sesudah data peserta pembinaan seni suara dan musik dihimpun, dilakukan uji kepercayaan diri tampil di depan umum. Selanjutnya dilaksanakan pengembangan sumber daya manusia di Desa Bligo yang berminat pada penguatan bakat menyanyi dan bermusik hingga mampu tampil di depan umum dan menjamu para pewisata di Kampoeng Wisata Titik Nol Jateng, Desa Bligo.

\section{HASIL DAN PEMBAHASAN}

Atraksi wisata di Kampoeng Titik Nol Jateng perlu dioptimalkan dengan berbagai upaya pemberdayaan warga masyarakat setempat, termasuk generasi muda dan anak-anak. Sebelum pembinaan, Komunitas Pembinaan Seni Suara dan Musik di Desa Bligo dan Pakunden, Ngluwar, Jawa Tengah belum banyak memiliki tenaga ahli di bidang seni suara dan musik. Pengajar ahli yang menjadi pengembang bakat masyarakat dalam bidang seni suara dan musik belum terkondisikan dengan baik. Namun, peminat bahkan bibit unggul dalam bidang seni suara dan musik telah banyak. Tidak sedikit dari mereka memiliki kemampuan yang baik dalam bidang seni suara dan musik. Bahkan di Dusun Curah, ada satu anak yang telah mewakili sekolahnya untuk lomba macapat di tingkat provinsi.

Di Dusun Blaburan, Dusun Curah, dan Dusun Jenis dilakukan pengembangan dan pembinaan seni suara dan musik, yang meliputi unsur-unsur musik, instrumen musik, jenis lagu, membaca dan memahami not angka/balok, teknik produksi suara, pengenalan nada, dan hamorni serta penghayatan dalam menyanyikan sebuah lagu. Peserta pembinaan seni suara dan musik di Dusun Blaburan sebanyak 14 orang, dari Dusun Curah sebanyak 27 orang, dan dari Dusun Jetis sebanyak 24 orang. Adapun di Dusun Blaburan sebelum adanya pembinaan seni suara dan musik, banyak 
anak di bawah usia 12 tahun memiliki minat dan potensi, bahkan modal percaya diri yang dapat dikembangkan lebih jauh lagi dalam bidang seni suara dan musik. Mereka pada umumnya belajar mandiri sehingga kurang ada pengenalan tentang seni suara dan alat musik untuk mereka sehingga membuat potensi mereka kurang berkembang dan berdaya untuk atraksi wisata hiburan pertunjukan musik. Dengan demikian, perlu adanya pembinaan dalam bidang seni suara dan musik di dusun tersebut.

Demikian juga, kegiatan pembinaan dan pelatihan seni suara dan musik di Dusun Jetis, Pakunden, Ngluwar, Magelang, Jateng diikuti sebanyak 24 anak-anak yang rata-rata berusia di bawah 15 tahun. Sesuai minat dan bakat serta orientasi ke depan sebagai penyaji atraksi wisata di Kampoeng Wisata Titik Nol Jateng dengan pengembangan dan pembinaan secara intensif 30 hari dari P3 Wilsen LPM ISI Yogyakarta diharapkan dapat mengembangkan potensi dalam seni suara (seni vokal) dan bermusik untuk memperkuat atraksi wisata yang modern dan populer di Kampoeng Wisata Titik Nol Jateng.

Awal pembinaan seni suara dan musik yang dihimpun data para peserta dari Blaburan, Jetis, dan Curah menunjukkan data: kategori Sangat Baik tidak ada atau 0; Baik ada 13 peserta atau 20\%; Cukup ada 17 peserta atau 26,1\%; dan klasifikasi Buruk ada 31 peserta atau 47,7\%, serta yang di kelompok Sangat Buruk tidak ada atau 0. Artinya, pada awal pelatihan hanya ada 30 peserta yang berkemampuan Baik dan Sangat Baik atau seluruhnya 46,1\% saja.

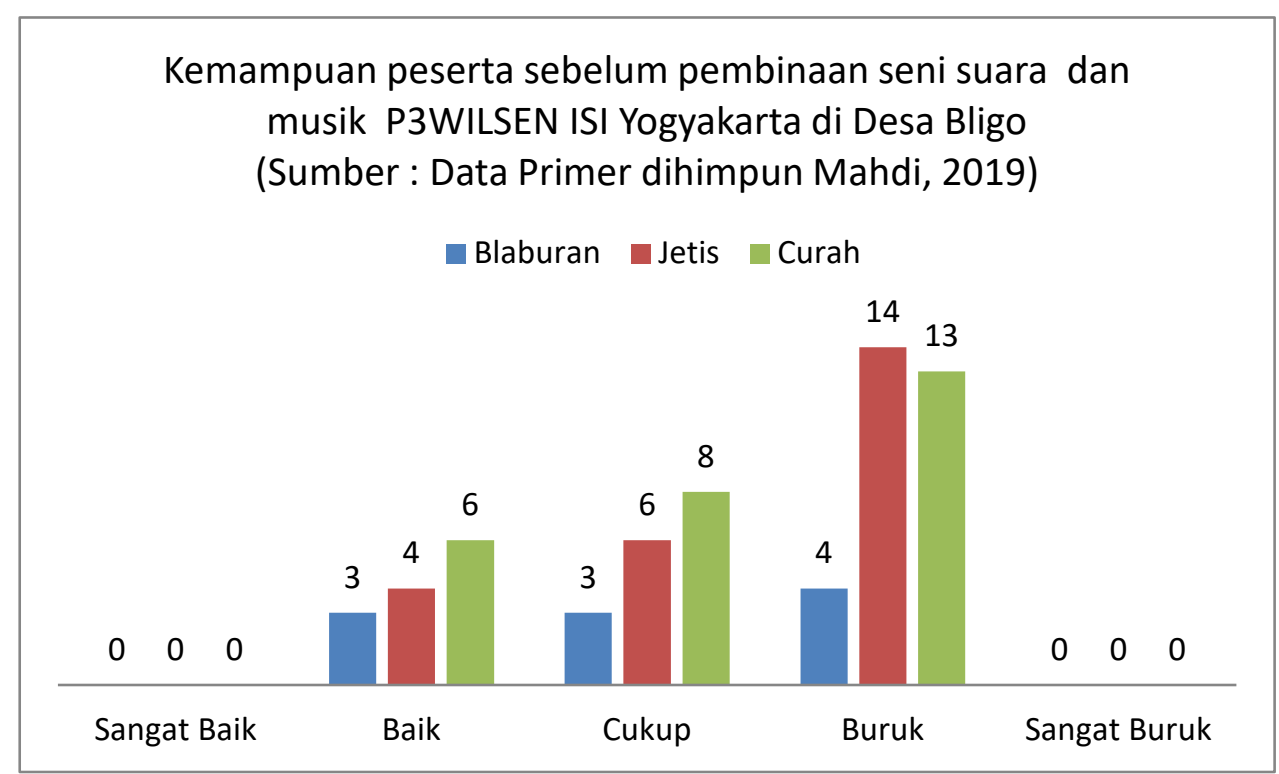

Grafik 2 Keadaan peserta sebelum pembinaan (prates) seni suara dan musik di Desa Bligo, Ngluwar, Kabupaten Magelang (Didata: Mahdi Naufal, 2019)

Data keadaan peserta awal pembinaan dan pengembangan seni suara dan musik dengan melatih dan memberdayakan kemampuan menyanyi peserta. Peserta pembinaan seni suara dan musik dengan jumlah jam pembinaan selama 2 jam x 25 
pertemuan, yang meliputi dasar-dasar produksi suara selama 4 jam, penguasaan nada dan artikulasi selama 4 jam, penghayatan lagu dan ekspresi penyanyi selama 4 jam, praktik menyanyi tanpa iringan musik (instrumen) selama 4 jam, praktik menyanyi dengan iringan musik selama 4 jam, dan 5 jam untuk menyanyi di panggung diiringi musik (keyboard atau piano). Kegiatan menyanyi dapat meningkatkan kemampuan seni suara anak dalam bermusik memakai vokal untuk berekspresi dan menciptakan keindahan, rasa estetis, dan rasa musikal pada dirinya (Hasna, Abubakar, Saranani, 2019:205).

Tampaknya peserta pembinaan seni suara dan musik sudah mencapai pemahaman rasa estetis dan rasa musikal yang semakin baik. Hasilnya pada akhir pelaksanaan diperoleh data adanya peningkatan kemampuan peserta pembinaan seni suara dan musik. Peserta dengan kemampuan Sangat Baik sebanyak 18 peserta, kategori Baik ada 35 peserta, dan kelompok Cukup ada 12 peserta. Jadi, pembinaan dan pengembangan kemampuan seni suara dan bermusik dalam kategori Sangat Baik menjadi 27,7\% yang sebelumnya tidak ada yang termasuk Sangat Baik atau 0\%; berkategori Baik ada 53,8\% yang sebelumnya 20\% saja; dan berkategori Cukup ada 18,5\% semula ada yang berkategori Buruk ada 47,7\% sehingga pemberdayaan seni suara dan musik di Desa Bligo telah meningkatkan kemampuan bernyanyi peserta. Lihat Grafik 3 di bawah ini.

\section{Kemampuan peserta sesudah pembinaan seni suara dan musik P3WILSEN ISI Yogyakarta}

(Sumber: Data Primer dihimpun Mahdi, 2019)

Blaburan Jetis Curah

15

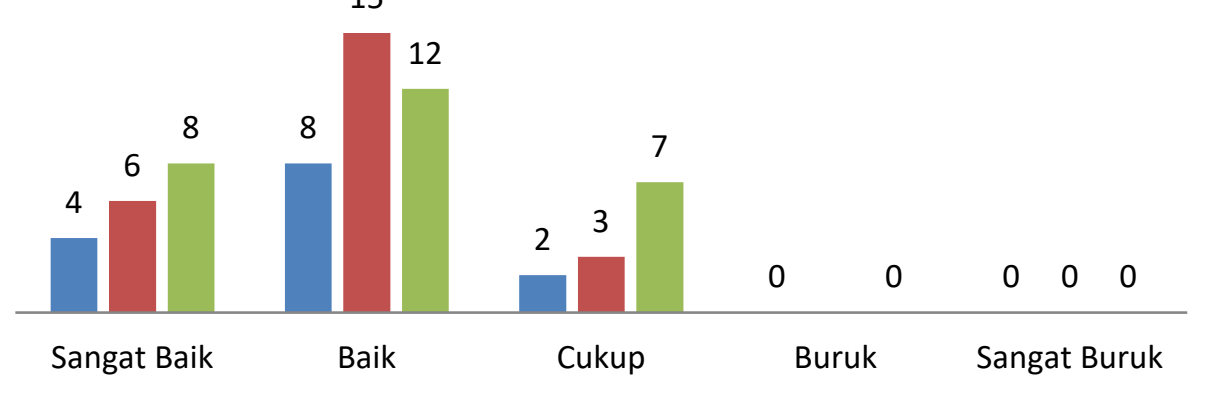

Grafik 3 Kemampuan peserta sesudah pembinaan seni suara dan musik menunjukkan peningkatan kemampuan bernyanyi sebagai atraksi wisata di Kampoeng Wisata Titik Nol Jateng, Desa Bligo (Didata: Mahdi Naufal, 2019)

Lagu yang dibawakan peserta adalah Padamu Negeri karya Ibu Sud, Guruku Tersayang karya Melly Goeslaw, Jerit Atiku (Via Vallen), Tatu (Didi Kempot) dinyanyikan Arda, Selow (Via Vallen), dan lagu populer lainnya hingga $D d u \quad D u D d u D u$ (Black Pink). Kemampuan menyanyi adalah di lagu pop Jawa (campursari), dangdut, 
lagu anak, dan lagu kebangsaan nasional Indonesia. Tantangan memberdayakan warga dalam menyanyi dan bermusik adalah tingkat percaya diri yang rendah. Tingkat percaya diri peserta pembinaan memengaruhi proses pemberdayaan dan komunikasi dengan Tim P3 Wilsen LPM ISI Yogyakarta. Sikap percaya diri harus dimiliki oleh setiap personal yang mampu menerima dirinya sendiri, mampu menghadapi tantangan baru atau mencoba sesuatu yang baru, tidak takut mengungkapkan pendapatnya di depan umum (banyak orang), dan mempermudah bergaul serta menangani berbagai tugas dengan mudah (Fatimah dan Muksin, 2017:100). Oleh sebab itu, diperlukan sumber daya manusia penyaji dan pendukung atraksi wisata yang memiliki percaya diri yang baik, tidak minder, dan berasa malu berlebihan. Model pembinaan seni suara dan musik menggunakan model pencerdasan emosi anak agar lebih percaya diri, bertanggung jawab, empati, dan memiliki rasa estetis. Kesuksesan seseorang dibekali dengan keterampilan intelektual dan kecerdasan emosi agar dapat mengotimalkan potensi diri dan bakat secara penuh (Uno, 2010).

Para peserta sebelum pembinaan seni suara dan musik dikelompokkan menjadi 5, yaitu Sangat Percaya Diri ada 6 peserta atau 9,2\% saja; lainnya 31 peserta atau 47,7\% termasuk Percaya Diri; ada 21 peserta Cukup Percaya Diri atau 23,3\%, serta ada 5 peserta atau 7,7\%, dan 2 peserta dengan kategori Sangat Kurang Percaya Diri atau $3,1 \%$. Upaya menumbuhkan rasa percaya diri dan praktik yang mencerdaskan emosi para peserta menjadi perhatian dan diutamakan kepada para peserta yang masih malu, kurang percaya diri, dan tingkat kecerdasan emosinya belum baik, seperti kurang bertanggung jawab dan kurang empati pada sesama peserta pemberdayaan seni suara dan musik.

Materi penguatan percaya diri disisipkan saat berlatih menyanyi dengan mengungkapkan "Aku paling cantik. Aku sangat hebat. Aku pasti bisa...." Selain itu, di setiap pertemuan mereka diajak tampil di panggung sehingga rasa malu semakin berkurang dan meningkatkan rasa percaya diri peserta. Tingkat rasa percaya diri perserta sesudah pembinaan seni suara dan musik di Desa Bligo (Grafik 5) yang menunjukkan bahwa yang berkategori Sangat Percaya Diri sebanyak 36 peserta atau 55,4\%; yang berkategori Percaya Diri ada 24 peserta atau 36,9\%; dan berkategori Cukup Percaya Diri ada 5 peserta atau $7,7 \%$. Modal percaya diri peserta pembinaan yang berkategori secara komulatif Sangat Percaya Diri dan Percaya Diri ada 97,3\% cukup memadai untuk mengembangkan potensi seni suara dan musik untuk atraksi wisata di Kampoeng Wisata Titik Nol Jateng di Desa Bligo, Ngluwar, Magelang. 


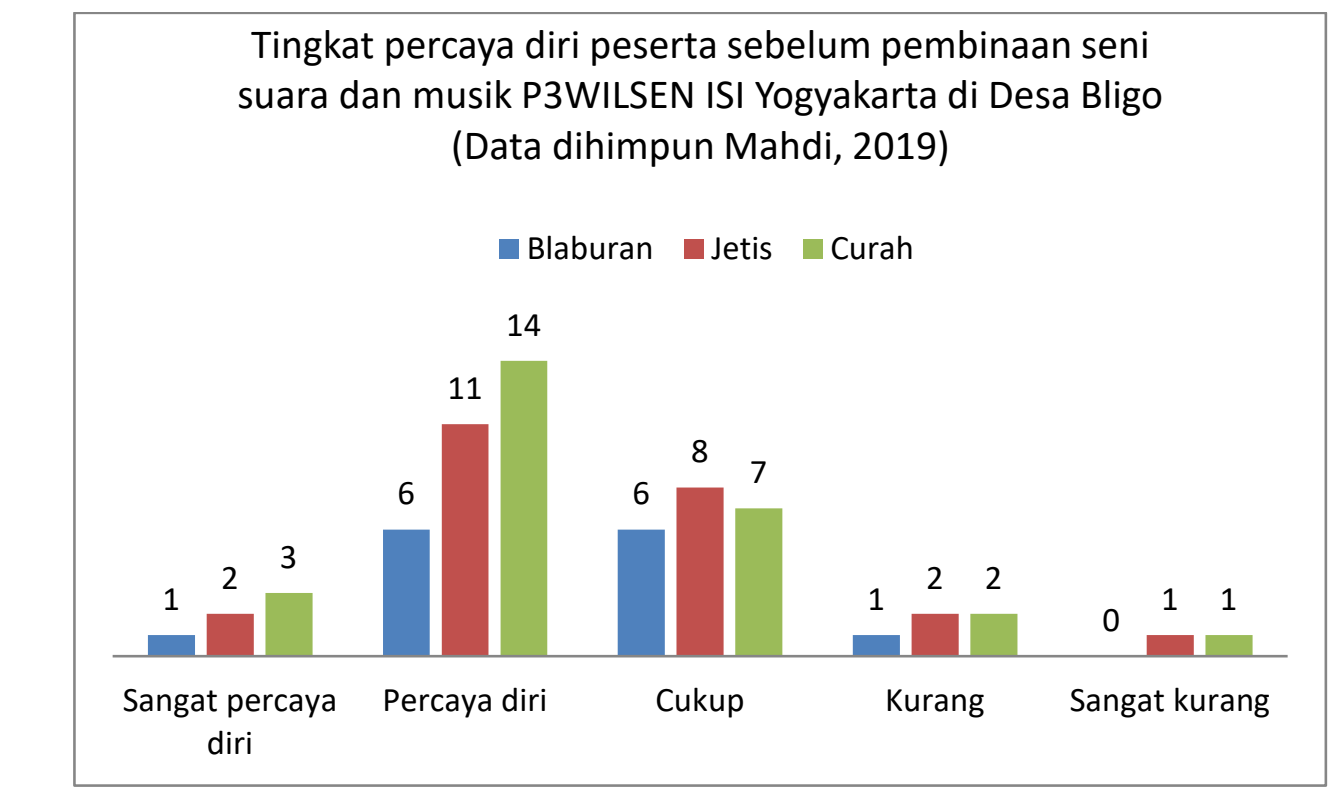

Grafik 4 Tingkat kepercayaan diri peserta sebelum pembinaan seni suara dan musik dari Blaburan, Jetis dan Curah untuk atraksi wisata di Kampoeng Wisata Titik Nol Jateng, Desa Bligo (Didata: Mahdi Naufal, 2019)

\section{Tingkat percaya diri peserta sesudah pembinaan Seni Suara dan Musik P3WILSEN ISI Yogyakarta di Desa Bligo \\ (Data dihimpun Mahdi, 2019)}

Blaburan Jetis Curah

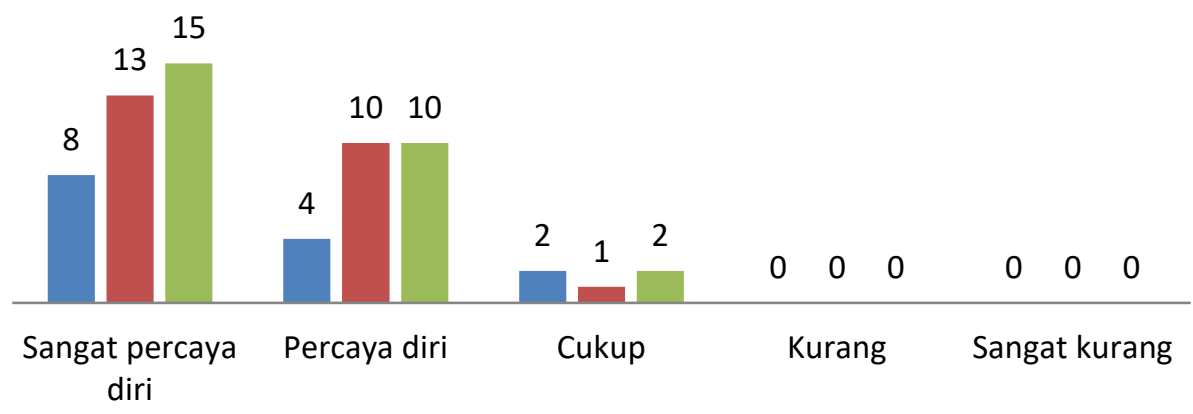

Grafik 5 Tingkat kepercayaan diri peserta sesudah pembinaan seni suara dan musik untuk atraksi wisata di Kampoeng Wisata Titik Nol Jateng, Desa Bligo (Didata: Mahdi Naufal, 2019)

Sesudah memberdayakan dasar-dasar produksi suara hingga menyanyi dengan bermusik serta memperkuat rasa percaya diri sumber daya seni suara dan musik maka dilakukan langkah selanjutnya, yaitu memfokuskan peminatan peserta pada jenis musik atau aliran musik tertentu. Para peserta setelah pembinaan seni suara dan musik menunjukkan minat yang beragam, yaitu sebagai penyanyi ada 22 peserta atau 33,8\%; sebagai pemusik ada 9 peserta atau 13,8\%; memilih bernyanyi dan bermusik ada 6 peserta atau 9,2\%; (lihat Grafik 6); dan yang hendak menjadi penyanyi bersama (koor) ada 
28 peserta atau 43,1\%. Minat peserta sesudah pelatihan sebagai bahan proyeksi untuk membuat atraksi wisata yang beragam dan berkualitas yang disajikan di Kampoeng Wisata Titik Nol Jateng

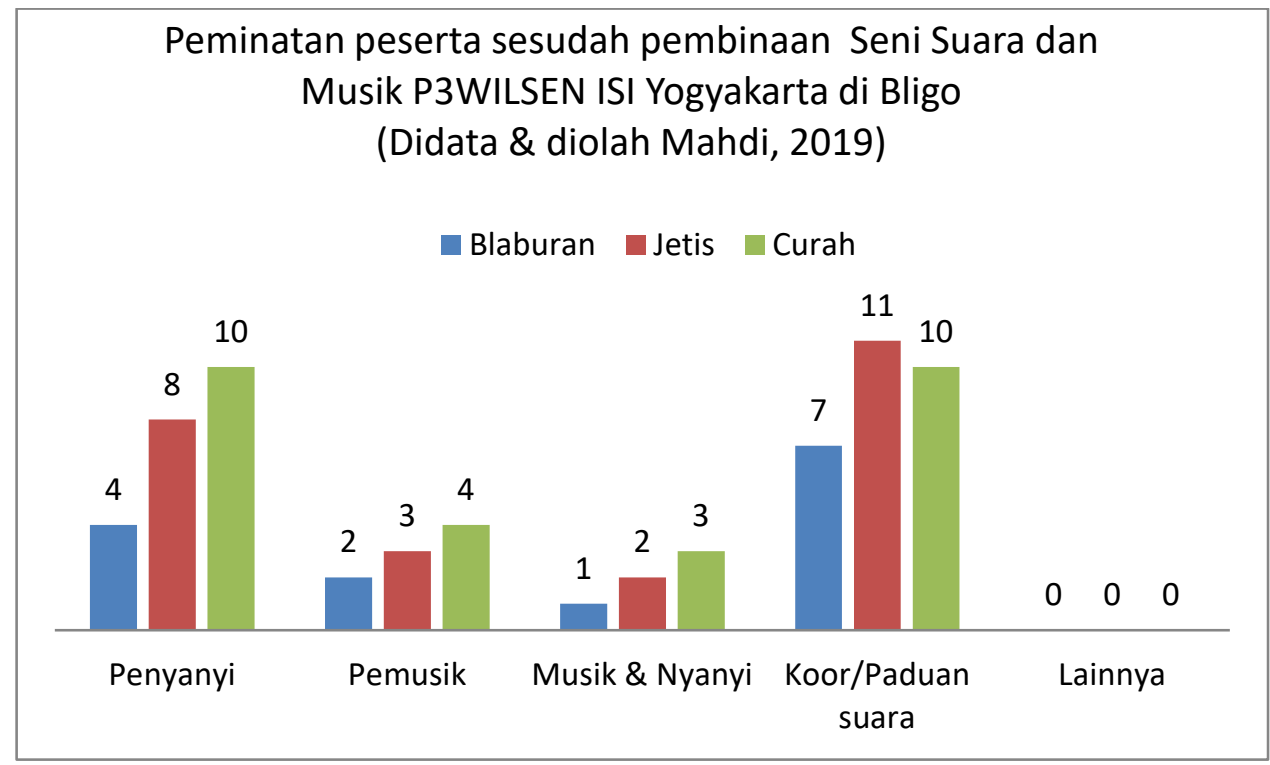

Grafik 6 Minat peserta sesudah pembinaan seni suara dan musik dari Blaburan, Jetis, dan Curah untuk atraksi wisata di Kampoeng Wisata Titik Nol Jateng, Desa Bligo (Didata: Mahdi Naufal, 2019)

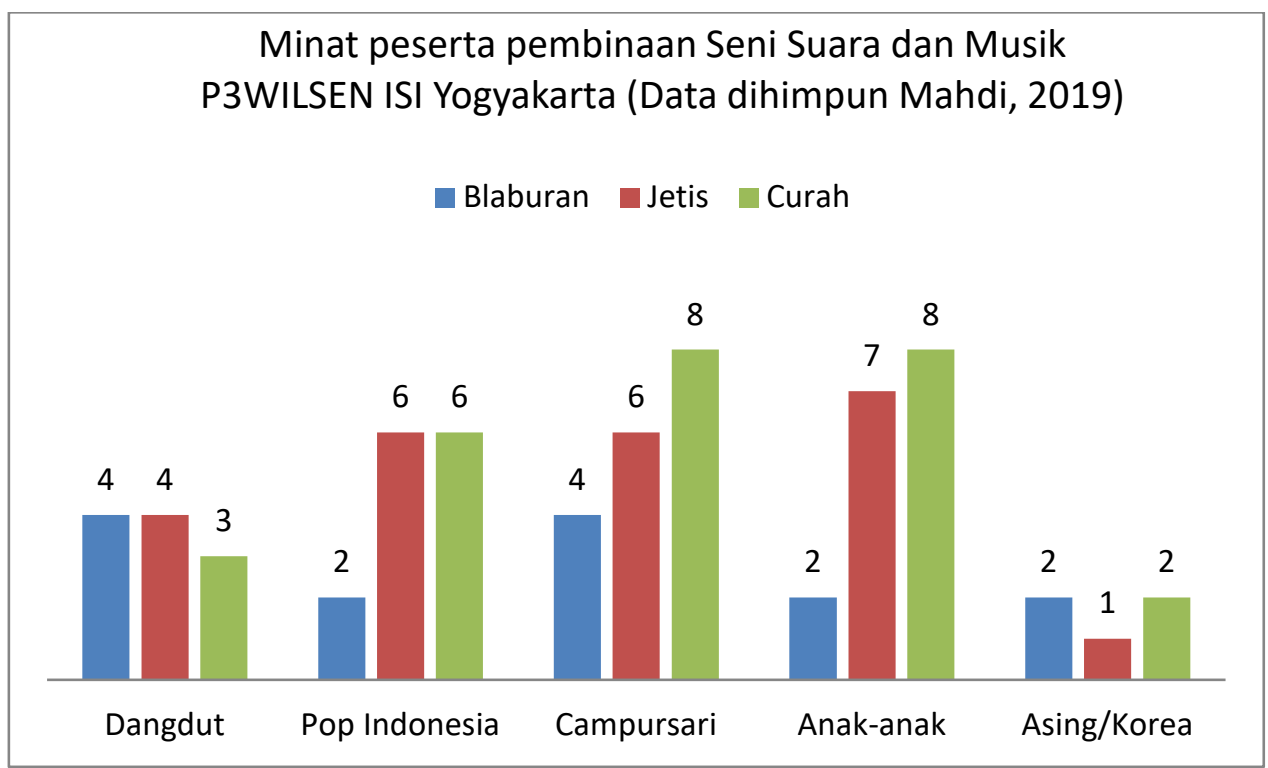

Grafik 7 Minat peserta sesudah pembinaan seni suara dan musik di Desa Bligo dengan jenis musik untuk atraksi wisata di Kampoeng Wisata Titik Nol Jateng, Desa Bligo

(Didata: Mahdi Naufal, 2019)

Para peserta belum seluruhnya menguasai jenis musik yang beragam dan terus berkembang. Oleh sebab itu, para peserta pembinaan seni suara dan musik ada lima kelompok minat, yaitu dangdut ada 11 peserta atau $16,9 \%$; yang memfokuskan pada 
lagu pop Indonesia ada 14 peserta atau 21,5\%; jenis lagu campur sari ada 18 peserta atau 27,7\%; lagu anak-anak ada 17 peserta atau 26,1\%; dan yang berminat lagu asing/Korea ada 5 peserta atau 7,6\%. Jadi, hasil dari pembinaan seni suara dan musik untuk atraksi wisata telah memiliki kemampuan menyanyikan lagu dangdut, pop Indonesia, anak-anak, campursari, dan lagu asing/Korea. Tindak lanjutnya adalah memberikan motivasi dan pembinaan lebih lanjut agar dapat menyanyi dengan penampilan gerak tari, tata rias, dan tata busana yang memikat serta menarik pewisata.

\section{SIMPULAN}

Pembinaan seni suara dan musik di Desa Bligo, Ngluwar, Magelang dapat menjadi potensi atraksi wisata di Kampoeng Wisata Titik Nol Jateng. Melalui Tim P3 Wilsen LPM ISI Yogyakarta kegiatan ini memberikan kontribusi bagi kesejahteraan masyarakat sekitar destinasi wisata. Pelatihan yang dilakukan selama 50 jam pertemuan dan evaluasi selama 2 jam diperoleh hasil adanya peserta yang semakin mampu berseni suara dan bermusik dengn baik dan bahkan sangat baik, yaitu pada awal pelatihan hanya ada 30 peserta yang berkemampuan Baik dan Sangat Baik atau seluruhnya $46,1 \%$ saja, menjadi level Sangat Baik sebanyak 18 peserta; peserta dengan kemampuan menyanyi kategori Baik ada 35 peserta atau 53 peserta (81,5\%). Tingkat rasa percaya diri peserta juga meningkat signifikan dari jumlah Sangat Percaya diri dan Percaya Diri ada 37 peserta (ada 6 peserta atau 9,2\% saja, lainnya 31 peserta atau 47,7 \% termasuk Percaya Diri) menjadi sejumlah peserta yang berkategori Sangat Percaya Diri dan Percaya Diri sebanyak 60 peserta atau 92,3\% (36 peserta atau 55,4\% sebagai Sangat Percaya Diri dan Percaya diri ada 24 peserta atau 36,9\%). Minat para peserta juga sudah diklasifikasikan antara sebagai penyanyi atau pemusik atau keduanya, yaitu ada 22 peserta atau 33,8\%; sebagai pemusik ada 9 peserta atau $13,8 \%$; memilih bernyanyi dan bermusik ada 6 peserta atau 9,2\%; dan yang hendak menjadi penyanyi bersama (koor) ada 28 peserta atau $43,1 \%$. Selain itu, untuk menelusuri jejak minat lagu pilihan yang akan dinyanyikan dangdut ada 11 peserta atau 16,9\%; yang memfokuskan pada lagu pop Indonesia ada 14 peserta atau 21,5\%; dan jenis lagu campursari ada 18 peserta atau 27,7\%; peserta yang memilih lagu anak-anak ada 17 peserta atau 26,1\%; dan yang berminat lagu asing/Korea ada 5 peserta atau 7,6\%. Potensi masyarakat dalam mengembangkan atraksi wisata pertunjukan budaya di Kampoeng Wisata Titik Nol Jateng semakin maju dan bermanfaat bagi kesejahteraan ekonomi dan sosial masyarakatnya. 


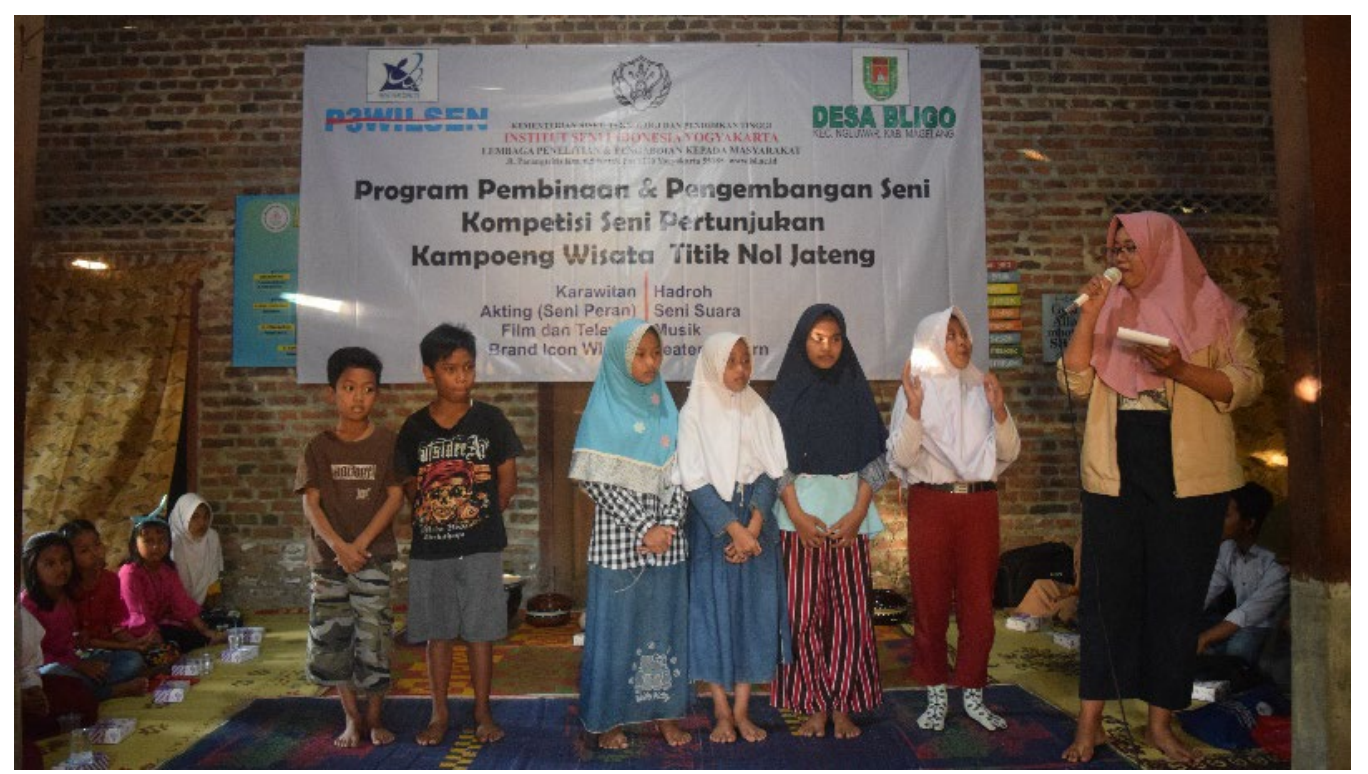

Gambar Pemberian sertifikat kepada peserta sesudah pembinaan seni suara dan musik di Desa Bligo untuk atraksi wisata di Kampoeng Wisata Titik Nol Jateng, Desa Bligo (Foto: Mahdi Naufal, 2019)

\section{SARAN}

Perlu dilanjutkan penguatan kemampuan peserta pembinaan seni suara dan musik di Kampoeng Wisata Titik Nol Jateng, yaitu penyediaan sound system yang representatif dan berkualitas bagus, melatih gerak tari sederhana pendukung tampilan saat bernyanyi dalam atraksi wisata, memperkuat kemampuan tata rias, dan tata busana serta pengadaan instrumen musik keyboard, bass gitar atau kendang, dan drum yang bagus sehingga penampilan mereka semakin memikat pewisata.

\section{UCAPAN TERIMA KASIH}

Terima kasih diucapkan kepada Dr. Yudik Prasetyo, M.Kes. selaku Pembina Kampoeng Wisata Titik Nol Jateng, Blaburan, Bligo, Ngluwar, Magelang.

\section{DAFTAR PUSTAKA}

Khaliq, Abdul. (2020). Peran Riset dan Pengembangan (R \& D) Akademis Terhadap Pertumbuhan Ekonomi. Jurnal Ekonomi Kuantitatif Terapan, 13(1), 115-
132.

http: / / ojs.unud.ac.id/index.php/jekt.

Hasna, Sitti Rahmaniar Abubakar, Muhammad Safuddin Saranani. (2019). Meningkatkan Kemampuan Seni Suara Anak Melalui Kegiatan Bernyanyi. Jurnal Riset Golden Age PAUD UHO, 2(3), 204 213.

http: / /journal.uho.ac.id/index.php/jg eg.

Iim Fatimah, Ucin Muksin, \& A. S. (2017). Peningkatan Ras Percaya Diri Anak Yatim dan Dhuafa Melalui Bimbingan Konseling Islam. Irsyad: Jurnal Bimbingan, Penyuluhan, Konseling dan Psikologi Islam, 5(1), 99-122. https://jurnal.fdk.uinsgd.ac.id/index.p $\mathrm{hp} /$ irsyad.

Machfudz, M. (2012). Riset dan Pengembangan Keilmuan: Sebuah Pendekatan Integratif. Iqtiishoduna, 8(1). http: / /jurnal.uin-mala.ac.id.

Ni Wayan Alieq Arista, I Gede Sutarya, I. K. A. W. (2017). Pengelolaan Seni Mempantigan Sebagai Atralsi Wisata di Desa Batubulan Kabupaten Gianyar. 
Jurnal Penelitian Agama Hindu, 1(1117122).

http: / / ejournal.ihdn.ac.id/index.php/ JPAH.

Putri, E. D. H. (2016). Pengembangan Desa Wisata Sidoakur dalam Upaya Pemberdayaan Masyarakat Sidokarto,
Godean, Sleman. Media Wisata, 14(2), 503-511.

amptajurnal.ac.id/index.php/MWS.

Uno, H. B. (2010). Orientasi baru dalam Psikologi Pembelajaran. Bumi Aksara.

Zalukhu, K. M. \& S. (2009). Panduan Dasar Pelaksanan Ekowisata. Unesco Office. 
